\title{
Factors Affecting College Students' Continuous Intention to Use Online Course Platform
}

\author{
Mengting Chen ${ }^{1} \cdot$ Xuan Wang $^{1}$ (D) Jixin Wang $^{2} \cdot$ Can Zuo $^{2} \cdot$ Jun Tian $^{2} \cdot$ Yongpeng Cui $^{3}$
}

Received: 27 September 2020 / Accepted: 1 February 2021 / Published online: 25 February 2021

(c) The Author(s), under exclusive licence to Springer Nature Singapore Pte Ltd. part of Springer Nature 2021

\begin{abstract}
In recent years, online learning model has become the mainstream in higher education. The cooperation between universities and Internet education platforms provides a good learning environment and abundant online elective courses for college students, but the practical teaching effect is not ideal. Therefore, based on the Universal Theory of Acceptance and Use of Technology (UTAUT), this study introduced the perceived cost and content quality to build a model of college students' continuous intention to use online course platforms, and used structural equation model to study the relationship among the variables. The results showed that effort expectancy and social influence affected continuous intention indirectly via performance expectancy; content quality indirectly affected continuous intention through effort expectancy, performance expectancy and effort expectancy-performance expectancy; perceived cost had a significant negative effect on continuous intention. These research results provide new ideas for the design and development of online course platform.
\end{abstract}

Keywords College student · UTAUT · Continuous intention · Online course platforms

\section{Introduction}

With the rapid development of information and communication technology, distance learning has been widely used by universities who are using online learning platforms [1]. In distance learning, online learning platform is regarded as an autonomous learning platform for learners' collaborative learning, which is a medium to help learners acquire, construct, and share knowledge. The massive open online course (MOOC) platform is popular among many learners because of its openness, individuation, autonomy, flexibility and rich resources. Therefore, while building their own MOOC

This article is part of the topical collection "Innovation and Technology for Smart Learning" guest edited by Lam-for Kwok, Junjie Shang, Shinichi Sato and Richard Li.

* Xuan Wang

wangxuan9@mails.ccnu.edu.cn

1 National Engineering Research Center for E-Learning, Central China Normal University, Wuhan, China

2 School of Educational Information Technology, Central China Normal University, Wuhan, China

3 Co-Innovation Center of Informatization and Balanced Development of Basic Education, Central China Normal University, Wuhan, China learning platforms, colleges and universities also cooperate with china's famous online education institutions (online course platforms such as Chaoxing Erya, Cloud classroom of Netease, Zhihuishu, etc.) to provide students with a variety of online general courses. Students need to complete the online courses to receive credits. Network elective courses are generally designed for freshmen and sophomores. This can arouse students' awareness of using the online course platforms for learning and improve the frequency of students' use of network course platforms. Before entering the university, high school students are used to face-to-face teaching in traditional classroom. To some extent, using network course platform is a new learning method.

During the COVID-19 pandemic, large-scale online teaching practice once again tested the advantages of online learning. However, a number of investigations on the current situation of students' online learning show that students had a poor attendance rate and continuous intention to learn. There is far from our expectation of helping students achieve better learning effect through online learning platforms. Therefore, this study explores the influencing factors of college students' continuous intention to learn using online course platforms through empirical research, so as to put forward reasonable suggestions for improving the effectiveness of online teaching. 


\section{Related Work}

\section{Online Course Platforms}

In this study, online course platforms refer to the learning platforms that provide online courses for users. These learning platforms collect high-quality curriculum resources and provide students with rich choices and learning experiences. For example, the famous online course platforms in China, such as XuetangX, China University MOOC and Cloud Classroom of Netease have more than 1000 online courses, respectively, and they are also the most frequently used online learning platforms among Chinese college students[2]. The online course platforms have many advantages, and can establish classroom in the air for students and teachers in different regions to solve the problem of resources shortage in local colleges and universities. Therefore, many universities have established online course platforms for online courses. Students' satisfaction with online course platforms largely determines the adoption of online course platform.

\section{UTAUT}

UTAUT (Unified Theory of Acceptance and Use of Technology) was put forward by Venkatesh and others in 2003, which integrated the Theory of Reasoned Action (TRA), Technology Acceptance Model (TAM), Motivational Model (MM), Theory of Planned Behavior (TPB), Combined TAM and TPB (C-TAM-TPB), Model of PC Utilization (MPCU), Innovation Diffusion Theory (IDT), Social Cognitive Theory (SCT) and more effective explanation of personal acceptance of information systems [3-5]. Since the UTAUT model was formed, a large number of references in academic works have been done to explore the user's continuous intention to use new technology. For example, the UTAUT model has received limited validation in education, such as e-learning in the workplace [6] and website use in higher education [7]. Compared with the single theory, the UTAUT model can explain $70 \%$ of the variance in the evaluation of users' acceptance of new technology [8]. Williams et al. reviewed the 870 academic works cited by UTAUT and found that most of the articles cited the modified model used some of the structures, while a few adopted all of them, and the moderating factors did not necessarily need to be considered [9]. Therefore, based on the UTAUT model and combined with the characteristics of online learning environment, this study introduced some new variables to construct the influencing factor model of college students' continuous intention to use online learning platforms.

\section{Performance Expectancy}

Performance expectancy (PE) refers to the degree that an individual believes that using a specific system can improve his or her work performance. PE is similar to perceived usefulness in TAM, comparative advantage in the innovation diffusion model and it is proved that PE is the most important factor affecting users' use intention. In UTAUT, PE is considered to be the direct influence factor of behavioral intention. In this study, performance expectancy is used to describe the expectations of college students to improve learning performance, expand professional skills and meet their own learning needs using online course platform. As shown in the literature, PE is an important predictor of continuous intention in blended learning or online learning [10]. Learners' criteria for evaluating the usefulness of technology depend on their expectations that technology will help improve results and achieve goals. Online learning is a new trend in higher education. Therefore, this study is to investigate learners' sustained use intention to online course platform based on this factor.

\section{Effort Expectancy}

Effort expectancy (EE) refers to the ease with which individuals use the system. EE is similar to perceived ease of use in TAM and complexity in MPCU. It is considered to have a significant impact on use' intention. In this study, EE refers to the amount of effort, time, and cognition that students feel is required to use an online course platform without interruption. TAM and TAM2 illustrate the importance of perceived ease of use in determining perceived usefulness and user attitudes towards technology. Ahmed pointed out in his research that learners, especially in non-compulsory courses, are not willing to continue to use the online system if they encounter difficulties in using it, and may tend to abandon the course or find alternative learning environment [11]. Based on these findings, effort expectancy is considered to be one of the influencing factors of performance expectancy and continuous intention to use online course platform.

\section{Social Influence}

Social influence (SI) is defined as the degree to which a person believes that someone (such as friend and family) important to him or her should use the new system. SI is similar to the subjective norm in TRA and image in IDT. In this study, social influence refers to that learners may be encouraged by their classmates, teachers, and others around them to choose to use the online course platform. In the early stage of technology adoption, social influence will significantly affect the use of intention. Brocke, Richter and Riemer believe that the 
social reason for students to connect with friends and peers is the tendency to affect acceptance [12]. This study included the relationship between social norms, perceived usefulness and behavioral intention in e-learning proposed by Cho [13], and considered that social influence has a significant positive impact on performance expectancy and behavior intention.

\section{Content Quality}

Online learning content design promotes the effective conditions of deep learning. Online course content consists of a set of pre-arranged, hyperlinked and interrelated courses. It includes not only the learning activities and materials supported by interactive multimedia but also the auxiliary learning tools (such as social network tools, bulletin boards, learning resource push tools, etc.). Altaher believes that the quality of online course content is not only determined by the specific content but also how the curriculum objectives, contents, activities and tasks of the relevant content are organized and updated to promote the occurrence of effective learning [14]. Altaher further pointed out that reasonable content design, organization and quality can not only help learners quickly access learning resources, but also affect students' motivation to continue learning. In this study, content quality refers to the two dimensions of teaching quality and assisted learning. Teaching quality includes the quality of video recording, the rationality of content organization, the key and difficult points of content; the auxiliary learning includes the rationality of video length, online testing, repeated learning, etc. Bhuasiri et al. believe that curriculum quality and self-efficacy are the key factors affecting the success of e-learning in developing countries [15]. Lin conducted a survey on the factors influencing students' willingness to accept and use the e-learning system and found that curriculum quality has a significant positive impact on perceived usefulness and perceived ease of use [16]. Therefore, this study believes that content quality has a positive and significant impact on performance expectancy, effort expectancy and continuous intention.

\section{Perceived Cost}

Perceived cost (PC) refers to students' perception of the expenses they need to pay when they buy paid courses. In previous studies, the perceived cost has been proved to have a significant negative impact on the purchase intention of consumers [17]. In the early days, MOOC platform provided free course videos, assignments and certificates. However, as MOOC suppliers began to adopt a commercial mode, some course resources were put into the charging ones, such as certificates and grading assignments.It also designed many fully-paid courses to charge more from users. For example, foreign EDX platforms launched fully-paid vocational education courses, and Coursera launched a professional subscription, that is, students can pay by month if they want to obtain advanced courses. China's MOOC platforms also adopt the same payment mode, including the acquisition of certificates, and the courses and resources that need to be paid [18].

Kim pointed out that without experience in the use of new technologies such as Mobile-Internet, customers cannot judge whether the cost is high or low[19]. Therefore, perceived cost is used to describe students' perception on the cost and relative value of the online course platforms that they experienced. In the literature on mobile commerce adoption intention, the perceived price has been proved to be negatively correlated with users' perceived satisfaction and continuous use intention[20].

\section{Continuous Intention}

In this study, continuous intention refers to learner's behavioral tendency and attitude towards learning on the online course platform in the future. Learner's behavioral intention is the dynamic belief for implementing behavior.

\section{Research Model and Hypotheses}

Combine with the original UTAUT model and the newly introduced influencing factors discussed above, a framework model is proposed in this paper, aiming to study the influencing factors of students' continuous intention to use the online course platforms, and how these factors affect students' continuous intention to use the online course platforms. The proposed model, as shown in Fig. 1, is mainly consisted of six variables: performance expectancy, effort expectancy, social influence, content quality, perceived cost, and continuous intention. Performance expectancy is considered as a determinant or mediating factor between effort expectancy, social influence and continuous intention. Moreover, performance expectancy and effort expectancy is considered as mediating factors between content quality and continuous intention.

Specifically, we proposed the following hypotheses:

H1 Learner's performance expectancy is positively related to continuous intention to use online course platforms.

H2a Learner's effort expectancy is positively related to performance expectancy.

$\mathrm{H} 2 \mathrm{~b}$ Learner's effort expectancy is positively related to continuous intention to use online course platforms.

$\mathrm{H} 2 \mathrm{c}$ Performance expectancy plays a mediating role between effort expectancy and continuous intention to use online course platforms. 
Fig. 1 Research framework

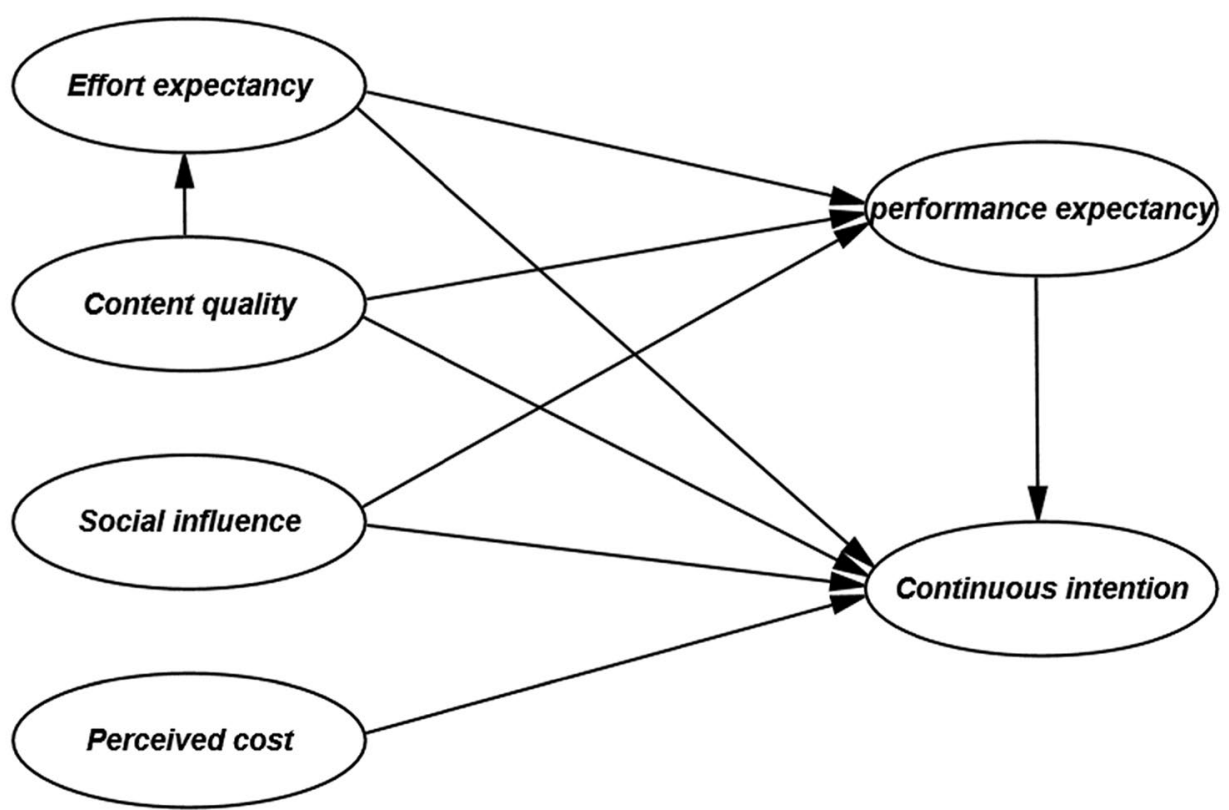

H3a Online courses' content quality is positively related to learners' continuous intention to use online course platforms.

$\mathrm{H} 3 \mathrm{~b}$ Online courses' content quality is positively related to performance expectancy.

H3c Online courses' content quality is positively related to effort expectancy.

H3d Performance expectancy plays a mediating role between online courses' content quality and continuous intention to use online course platforms.

$\mathrm{H} 3 \mathrm{e}$ Effort expectancy plays a mediating role between online courses' content quality and continuous intention to use online course platforms.

H3f Performance expectancy and effort expectancy play as the mediation between online courses' content quality and learners' continuous intention to use online course platforms.

$\mathrm{H} 4 \mathrm{a}$ Social influence is positively related to performance expectancy.

$\mathrm{H} 4 \mathrm{~b}$ Social influence is positively related to continuous intention to use online course platforms.

$\mathrm{H} 4 \mathrm{c}$ Performance expectancy plays a mediating role between social influence and continuous intention to use online course platforms.

H5 Learners' perceived cost of online courses is negatively related to continuous intention to use online course platforms.

\section{Methodology}

\section{Participants and Setting}

Besides face-to-face teaching in the classroom, college students also need to complete online elective courses. In addition, students would also use online course platforms to meet their other individualized learning needs. When learning the online courses on the platforms, learners can participate in different learning activities to realize self-directed learning besides completing the learning contents, e.g. discuss and answer questions with teachers and classmates in the online learning environment, view the updated information related to the classroom, and complete the tasks assigned by the classroom through online submission. Therefore, the research objects of this paper are the students who have participated in or are participating in online elective courses. To ensure the validity of the data, the paper questionnaires were used for the survey among students, including basic information of the students, the online course platforms used in online elective courses, and students' perception of using the online course platforms. 


\section{Instrumentation}

In this study, demographic information was collected through questionnaire first, and UTAUT, content quality and perceived cost were used to measure external and internal variables. To ensure the reliability and validity of each dimension in the questionnaire, this study sorted out and summarized the previous literature, cited authoritative scales on the measurement of the dimensions, and slightly adjusted the statement of the dimension measurement indicators according to the characteristics of the online course platforms. The questionnaire used a Likert five-point scale, ranging from $1=$ strongly disagree to $5=$ strongly agree. Twenty-two items were designed for performance expectancy, effort expectancy, social influence, content quality, perceived cost, and continuous intention. Confirmatory factor analysis was conducted after a small-scale pretest and deleted items with factor load lower than 0.7. The number and sources of measurement indicators of each variable are shown in Table 1. To ensure the accuracy of the questionnaire, it is essential to analyse the reliability and validity of the questonnaire. According to the general exploratory study proposed by Nunnally [21], Cronbach's $\alpha$ coefficient is greater than 0.6 , which is considered acceptable. Finally, the questionnaire contained 18 items on the scale, and the internal consistency reliabilities were all greater than 0.60 .

Table 1 Instrument

\begin{tabular}{lll}
\hline Variable & Items & Sources \\
\hline PE & 3 & Venkatesh [22] \\
EE & 3 & \\
SI & 2 & \\
CI & 3 & Almahamid [23] \\
CQ & 4 & Kim [24] \\
PC & 3 & \\
\hline
\end{tabular}

\section{Data Collection and Analysis Procedure}

Data were collected during November 2019. The online questionnaires and paper questionnaires were sent out, respectively. Before formally distributing the questionnaire, we sent 50 pre-test questionnaires to the students who have taken online courses to determine whether the statements of each item in the questionnaire can be understood by the respondents. In the formal questionnaire, a total of 337 valid samples (excluding 13 invalid samples) were recovered, with a recovery rate of $96.3 \%$. The collected data were input into Microsoft Excel and imported into SPSS 21.0 and Amos 20.0 for data analysis. Finally, the author used the structural equation model to analyze the relationship between independent variables and cloud classroom acceptance.

\section{Results}

\section{Descriptive Statistical Analysis of Sample Structure}

The participants in the study were 350 college students who have completed or are taking part in online courses in a normal university in central China. The descriptive statistics of this study is shown in Table 2. Most of the respondents are female, accounting for $74.2 \%(N=250)$ of the total sample, while male respondents accounted for $25.8 \%(N=87)$, and the gender distribution was close to the normal university's demographic composition. Most of the respondents are freshmen or sophomores with a few junior and senior students. The reason for the small sample number of junior and senior students is that they are busy looking for jobs or going for internships in these Grades. Therefore, they are not always in campus and have no time to participate in our research. In terms of the types of online courses, more than half of the students use the MOOC of China University and the cloud platform of the University for learning.

Table 2 Descriptive statistics

\begin{tabular}{llcc}
\hline Statistical characteristic & Category & Frequency & Percentage (\%) \\
\hline \multirow{2}{*}{ Gender } & Male & 87 & 25.80 \\
\multirow{3}{*}{ Education background } & Female & 250 & 74.20 \\
& Freshmen & 216 & 64.10 \\
& Sophomores & 117 & 34.70 \\
\multirow{3}{*}{ The online course platform used } & Junior and senior & 4 & 1.20 \\
& The MOOC of China University & 216 & 64.10 \\
& The cloud platform of the University & 182 & 54.00 \\
& Cloud classroom of Netease & 135 & 40.10 \\
& Zhihuishu & 84 & 24.90 \\
& Others & 69 & 20.50 \\
\hline
\end{tabular}


Table 3 Reliability and convergent validity

\begin{tabular}{|c|c|c|c|c|c|c|c|}
\hline Construct & Item & Factor loading & SE & $T$ & Cronbach's alpha & $\mathrm{CR}$ & AVE \\
\hline \multirow[t]{3}{*}{ PE } & PE1 & 0.846 & 0.020 & 42.890 & 0.824 & 0.895 & 0.740 \\
\hline & PE2 & 0.894 & 0.014 & 62.388 & & & \\
\hline & PE3 & 0.840 & 0.019 & 43.064 & & & \\
\hline \multirow[t]{3}{*}{ EE } & EE1 & 0.875 & 0.019 & 45.804 & 0.843 & 0.905 & 0.761 \\
\hline & EE2 & 0.893 & 0.017 & 51.366 & & & \\
\hline & EE3 & 0.848 & 0.025 & 33.378 & & & \\
\hline \multirow[t]{2}{*}{ SI } & SI1 & 0.877 & 0.028 & 31.803 & 0.698 & 0.869 & 0.768 \\
\hline & SI2 & 0.876 & 0.025 & 35.063 & & & \\
\hline \multirow[t]{3}{*}{ CI } & CI1 & 0.841 & 0.021 & 39.133 & 0.740 & 0.852 & 0.657 \\
\hline & $\mathrm{CI} 2$ & 0.803 & 0.027 & 29.993 & & & \\
\hline & $\mathrm{CI} 2$ & 0.788 & 0.028 & 28.102 & & & \\
\hline \multirow[t]{4}{*}{ CQ } & CQ1 & 0.806 & 0.023 & 34.731 & 0.756 & 0.845 & 0.578 \\
\hline & CQ2 & 0.780 & 0.033 & 23.728 & & & \\
\hline & CQ3 & 0.727 & 0.031 & 23.252 & & & \\
\hline & CQ4 & 0.726 & 0.040 & 18.008 & & & \\
\hline \multirow[t]{3}{*}{ PC } & PC1 & 0.784 & 0.047 & 16.857 & 0.800 & 0.883 & 0.716 \\
\hline & PC2 & 0.885 & 0.026 & 33.455 & & & \\
\hline & PC3 & 0.865 & 0.028 & 31.172 & & & \\
\hline
\end{tabular}

\section{Evaluation of the Measurement Model}

The measurement model test needs to test the reliability and validity of the scale. The construct of this study was tested by reliability, convergent validity and discriminant validity. According to Hair, the reliability test is "to evaluate the consistency between multiple measurement indicators of a variable", and the reliability test must be conducted before evaluating its validity[25]. Table 3 shows the results of the measurement model. In this study, Cronbach's alpha and composite reliability (CR) were used to test the internal consistency of constructs. As shown in Table 3, the combined reliability and Cronbach coefficient of all potential variables were in line with the recommended value of greater than 0.70 , indicating the good internal consistency among the measurement indicators. The average variance extracted (AVE) was used to evaluate the convergence validity of measurement models. AVE represents the ability of each tested variable to explain the mean-variance of potential variables. Hair pointed out that convergence validity can be established when the extracted average variance (AVE) is higher than 0.5 and the index factor load must be significant and higher than the acceptance level of 0.7. As shown in Table 2, both values were qualified, which means this study has an adequate convergent validity.

Discriminant validity refers to the low correlation and significant difference between latent variables. It can be evaluated by comparing the square root of mean-variance extraction and the correlation coefficient between variables. If the correlation coefficient between a variable and other variables is less than the square root of the mean-variance extraction of the variable, the discriminant validity of the variable is good [26]. The results of the discriminant validity test are shown in Table 4 . The values on the diagonal are the square root of AVE for each variable, and the other values are the correlation between the pairs of variables. The square root of AVE for each variable was
Table 4 Test of discriminant validity

\begin{tabular}{lrrrrrr}
\hline & PE & EE & SI & CI & CQ & PC \\
\hline PE & $\mathbf{0 . 8 6 0}$ & & & & & \\
EE & 0.366 & $\mathbf{0 . 8 7 2}$ & & & & \\
SI & 0.386 & 0.211 & $\mathbf{0 . 8 7 6}$ & & & \\
CI & 0.529 & 0.422 & 0.354 & $\mathbf{0 . 8 1 1}$ & & \\
CQ & 0.494 & 0.408 & 0.401 & 0.596 & $\mathbf{0 . 7 6 0}$ & \\
PC & -0.181 & -0.165 & -0.209 & -0.294 & -0.232 & $\mathbf{0 . 8 4 6}$ \\
\hline
\end{tabular}

Diagonal elements (bold) are the square root of the AVE for each construct; Off-diagonal factors correspond to construct intercorrelations 
Table 5 Test of discriminant validity

\begin{tabular}{lll}
\hline Model fit indices & Actual value & $\begin{array}{l}\text { Recom- } \\
\text { mended } \\
\text { value }\end{array}$ \\
\hline CMIN/DF & 2.109 & $\leq 5$ \\
RMSEA & 0.057 & $\leq 0.08$ \\
RMR & 0.034 & $\leq 0.09$ \\
GFI & 0.922 & $\leq 0.09$ \\
TLI & 0.929 & $\leq 0.09$ \\
CFI & 0.943 & $\leq 0.09$ \\
NFI & 0.898 & $\leq 0.09$ \\
\hline
\end{tabular}

higher than the correlation coefficient of other variables, indicating that the model has a good discriminant validity.

\section{Structural Equation Model}

The first step of model testing is to estimate the goodness of fit of the hypothesis study model. Table 5 indicates that the indices fit the model. This is typically done using a chi-square (CMIN or $\chi^{2}$ ). However, the $\chi^{2}$ tests are sensitive to sample sizes. The larger the sample size is, the greater the probability of $\chi^{2}$ tests rejection model is. This ratio should not exceed 5 for models with a good fit. Generally speaking, GFI, NFI, CFI and TLI that are greater than 0.90 indicate the model fits well (Bentler, 1989). In this study, Amos 24.0 software was used to estimate the fitting indexes [27]. The two fit indices for CFI, NFI and TLI are greater than the thresholds for acceptability 0.90 , and the NFI value 0.898 is lower than the commonly cited threshold of 0.90 ; however, this value is within the recommended range [28]. Hence, all the results meet the required standards, which proves the effectiveness of the external quality of the model.

\section{Hypotheses Testing}

The second step in model estimation is to examine each path significance in our research model and variance explained $R^{2}$ value by each path. Calculation results of structural equation model reports raw and standardized estimates for all specified paths, along with standard errors and test statistics for each path. Unstandardized path coefficients are shown in Fig. 2. Effort expectancy had a positive effect on performance expectancy $(\beta=0.155, t=2.561, P<0.05)$ and continuous intention $(\beta=0.146, t=2.358, P<0.05)$; Content quality can positively affect effort expectancy ( $\beta=0.545, t=6.354, P<0.001)$, performance expectancy $(\beta=0.429, t=4.373, P<0.001)$, and continuous intention $(\beta=0.569, t=5.021, P<0.001)$; Social influence can positively affect performance expectancy $(\beta=0.187, t=2.787$, $P<0.01)$, but has no significant effect on continuous intention $(\beta=-0.003, t=-0.04)$; Perceived cost had a negative impact on the continuous intention $(\beta=-0.121, t=-2.723$, $P<0.001)$; Performance expectancy had a positive impact on continuous intention $(\beta=0.994, t=8.436, P<0.001)$. The structural model explains $23 \%$ of the variance in effort expectancy, $43 \%$ of the variance in performance expectancy, $69 \%$ of the variance in continuance intention. Thus, H1, H2a, H2b, H3a, H3b, H3c, H4a, H5 were supported, while $\mathrm{H} 4 \mathrm{~b}$ was not supported.

To investigate the indirect effects of the dependent variable through the mediators, we performed bias-corrected percentile bootstrapping at a $95 \%$ confidence interval with 5,000 bootstrap samples [29]. If the confidence interval does not contain 0 , the corresponding mediating effect is significant. We followed the suggestions of Preacher and Hayes, and calculated the confidence interval of the lower and upper bounds to test whether the indirect effects were significant [30]. As shown in Table 6, the results of the bootstrap test confirmed the existence of a positive and significant
Fig. 2 Path analysis of every research constructs. Performance expectancy (PE), effort expectancy (EE), social influence (SI), content quality (CQ), perceived cost $(\mathrm{PC})$ and continuance intention (PI)

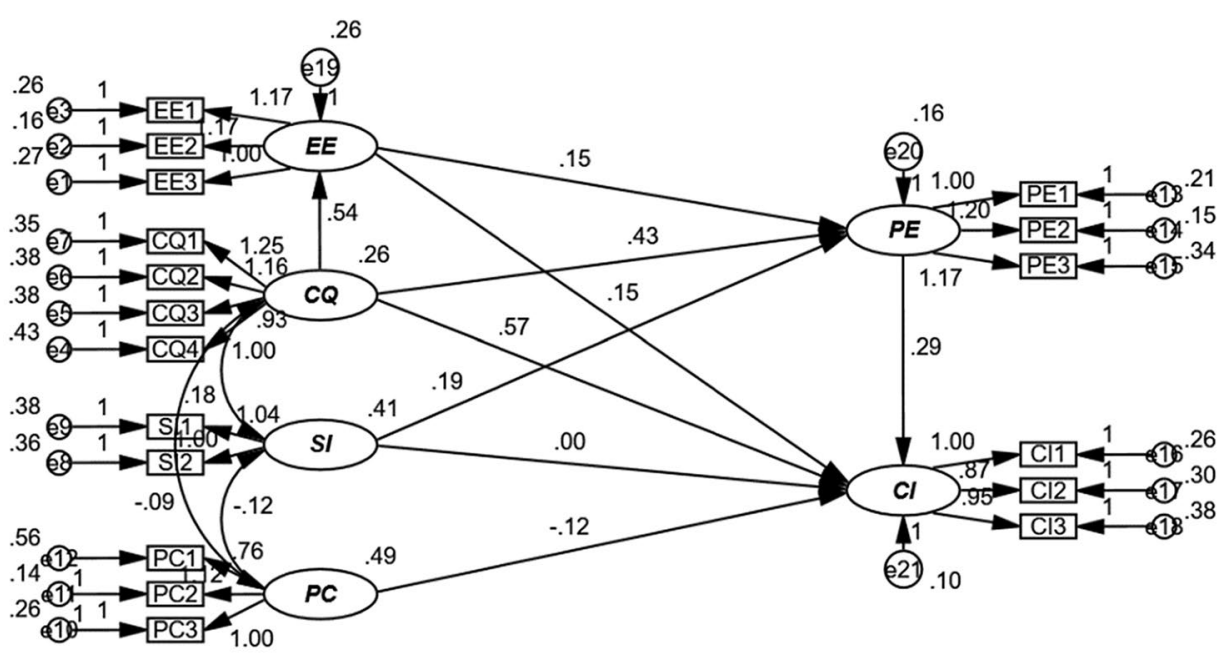


Table 6 Direct, indirect, and overall effects of the variables on continuance intention

\begin{tabular}{lcllll}
\hline Path & Point estimate & $\begin{array}{l}\text { Two-tailed } \\
\text { significance }\end{array}$ & $\begin{array}{l}\text { Bias-corrected percentile } \\
99 \% \mathrm{CI}\end{array}$ & $\begin{array}{l}\text { Effect } \\
\text { percent } \\
(\%)\end{array}$ \\
\cline { 4 - 5 } & & & Lower & Upper & \\
\hline Direct effects & & & & & \\
$\mathrm{EE} \rightarrow \mathrm{CI}$ & 0.146 & 0.031 & 0.014 & 0.294 & 76.44 \\
$\mathrm{CQ} \rightarrow \mathrm{CI}$ & 0.569 & 0.000 & 0.286 & 0.926 & 71.39 \\
$\mathrm{SI} \rightarrow \mathrm{CI}$ & -0.003 & 0.954 & -0.221 & 0.181 & \\
$\mathrm{Indirect} \mathrm{effects}$ & & & & & \\
$\mathrm{EE} \rightarrow \mathrm{PE} \rightarrow \mathrm{CI}$ & 0.045 & 0.038 & 0.002 & 0.125 & 23.56 \\
$\mathrm{CQ} \rightarrow \mathrm{EE} \rightarrow \mathrm{CI}$ & 0.080 & 0.023 & 0.013 & 0.180 & 10.04 \\
$\mathrm{CQ} \rightarrow \mathrm{PE} \rightarrow \mathrm{CI}$ & 0.124 & 0.014 & 0.027 & 0.288 & 15.56 \\
$\mathrm{CQ} \rightarrow \mathrm{EE} \rightarrow \mathrm{PE} \rightarrow \mathrm{CI}$ & 0.024 & 0.027 & 0.002 & 0.073 & 3.01 \\
$\mathrm{SI} \rightarrow \mathrm{PE} \rightarrow \mathrm{CI}$ & 0.054 & 0.027 & 0.005 & 0.167 & - \\
$\mathrm{T}$ & & & & & \\
$\mathrm{EE} \rightarrow \mathrm{CI}$ & & 0.013 & 0.043 & 0.332 & \\
$\mathrm{CQ} \rightarrow \mathrm{CI}$ & 0.191 & 0.013 & 0.543 & 1.103 & \\
$\mathrm{SI} \rightarrow \mathrm{CI}$ & 0.797 & 0.000 & -0.160 & 0.239 & \\
\hline
\end{tabular}

The mediating role of PE does not exist between SI and CI, so the effect percent is represented by “_” mediating effect for performance expectancy between effort expectancy and continuance intention (standardized indirect effect $\beta=0.045, P<0.05)$. Performance expectancy, effort expectancy, performance expectancy-effort expectancy have significant mediating effect between content quality and continuous intention (standardized indirect effect $\beta=0.124, P<0.05 ; \beta=0.090, P<0.05 ; \beta=0.024$, $P<0.05)$. However, although there is a significant indirect effect between social influence and continuous intention, the overall effect of social influence on continuous intention is not significant. Therefore, performance expectancy has no mediating effect between social influence and continuous intention $(\beta=0.054, P<0.05)$. The results supported $\mathrm{H} 2 \mathrm{c}$, $\mathrm{H} 3 \mathrm{~d}, \mathrm{H} 3 \mathrm{e}, \mathrm{H} 3 \mathrm{f}$ but H4c.

\section{Discussion}

This study examined how various factors affect the continuous intention, use of online course platforms based on the perspectives of the UTAUT, content quality and perceived cost. The results of the empirical analysis drowned a number of interesting insights: effort expectancy and social influence were found to be two important antecedents of performance expectancy, while content quality was found to be an important antecedent of effort expectancy, performance expectancy. In addition, effort expectancy, content quality, perceived cost and performance expectancy were found to be key antecedents of continuous intention.

Specifically, content quality was the critical factor with regard to effort expectancy. Confirmation was not only the key influential factor in relation to effort expectancy, but also the most influential among three antecedents on performance expectancy followed by social influence, effort expectancy. Similarly, content quality was the most influential among three antecedents on continuous, intention, with the relative importance being social influence, performance expectancy, effort expectancy, and perceived cost in that order. These findings were part consistent with the propositions of UTAUT, and contribute both theoretically and empirically to the literature on online course platform. The results of the empirical analysis are discussed in more detail below.

\section{Influence of UTAUT Constructs}

First of all, performance expectancy significantly affects learners' continuous intention to use the online course platforms. This indicated that the higher expectation of using the online course platforms to improve learning performance, the stronger continuous intention of learners to use online course platforms. Second, effort expectancy does not only directly and significantly affect learners' continuous intention to use online course platforms, but also indirectly affect their continuous intention to use the online course platform through performance expectancy. Performance expectancy partially mediates the relationship between effort expectancy and continuous intention. This result supports the previous findings of Heinrichs et al. [31] that the ease of use of online course platform and school or individual online learning conditions are the premise for learners to regard it as a useful learning tool, which will indirectly affect learners' intention to use it continuously. This is also the key factor to make the education platform more competitive. It was observed that the online course platforms that require less time and 
cognitive load will stand out in the competition of similar online education platforms. All these findings are consistent with the results of previous UTAUT related studies [32, 33], emphasizing that performance expectancy and effort expectancy are the two main factors for the continuous adoption of specific information systems. However, the results of this study show that social influence has no significant impact on performance expectancy and continuous intention. This is not consistent with the previous research results of UTAUT [34], but consistent with Wong's study [35]. Wong believes that the need for a sense of belonging increases with age. This means that social influence may have little or no influence on the behavioral intentions of the younger generation. The results from the descriptive analysis indicated that all participants were at a relatively young age of 18-21 years, making them less likely to be influenced by others. Learners' use of online learning platform depends more on the applicability and intention of the platform, and is less likely to be influenced by others.

\section{Influence of Content Quality}

Content quality is an important direct predictor of effort expectancy, performance expectancy and continuance intention. Moreover, content quality also indirectly affects the continuous intention through effort expectancy, performance expectancy and effort expectancy-performance expectancy. These three indirect effect chains play a partial mediation role with performance expectancy to be the most obvious one. This is consistent with Cheng [36]. These studies found that there was a significant positive correlation between content quality and the convenience and usefulness of using electronic whiteboard, which also supported the research results of Sharma and Channel that website quality has a direct impact on behavioral intention [37]. The results of this study confirmed that the ease in understanding and convenience in finding learning materials will directly affect students' beliefs in the performance expectancy of online course platforms and indirectly affect learners' continuous intention to use online courses simultaneously. If the online course platforms have simple navigation options and depression user friendly functions, such as testing, discussion and assignment tools, learners' use motivation can be improved through these simple designs. Furthermore, this study indicated that the quality of teaching content and the richness of learning resources will affect students' performance expectancy. The course content contains a variety of learning resources in different forms, such as hyperlinks, assignment tools, tests, discussions, presentations, lecture materials, syllabus, bulletin boards and course requirements. These resources are flexible for online learners and they can get access to them anytime and anywhere. These resources meet the curriculum objectives and the needs of students, which promote the learning process. Therefore, they believe that online course platforms are useful learning aids. Despite the above situation, some students reported that the content of some courses was lack of interactive multimedia and communication tools and the quality was also uneven, which did not reach their expectations. In turn, this has a negative impact on performance expectancy.

\section{Influence of Perceived Cost}

The results show that perceived cost has a significant negative impact on continuous intention. This result supports the previous findings of Chong. He believes that when users invest in unfamiliar new Internet technology, the higher the perceived cost, the less willingness the customers are to adopt the technology. The high price or the price they have to pay makes it impossible for users to try the service they are uncertain about. The higher the cost of online learning, the more likely it will be for college students to give up using the online learning platforms.

\section{Conclusions, Suggestions and Limitations for Future Research}

This study integrated the theoretical perspective of UTAUT with the e-learning continuance model to examine factors influencing college students' continuous intention to use online course platform. The results are as follows:

First, considering the influencing factors of UTAUT model, this study integrates new variables such as content quality and perceived cost to improve the UTAUT model. The results show that the improved model has good fitting degree, high adaptability and strong explanatory power.

Second, the performance expectancy, effort expectancy and content quality of learners are all the positive direct influencing factors of learners' continuous intention to use online course platform. The direct impact effect is in the order of content quality $>$ performance expectancy $>$ effort expectancy. In addition, the effort expectancy of learners on the online course platform will indirectly continuous intention through the performance expectancy; the quality of online course content will also indirectly affect the learners' continuous intention through the long-distance mediating path of effort expectancy and performance expectancy. Therefore, it can be considered that improving the ease of use of the online course platform and the quality of the course content can directly and indirectly promote learners' willingness to continue to use.

Third, learners' perception of the price of online course platform courses has a significant negative impact on their willingness to continue using. The higher the perceived cost of online learning, the lower the willingness to learn. 
Therefore, the setting of the course price structure of online course platform is one of the issues that the platform operators need to consider. After all, it is also one of the key factors in retaining users.

According to the above research conclusions, combined with the actual development situation of China's online course platform, this study puts forward the following suggestions:

To improve the quality of course resources in online course platforms, it calls for attention to the practicality and applicability of the courses. The degree of learners' expectation of the performance of online course platform and the perception of course quality are the important factors that affect their continuous intention to use the online course platforms. Since the college students had experiences in online course platforms when doing school elective courses they would pay more attention to the value and practicability of the course content when choosing online course platforms in the future. Therefore, it is suggested that courses on MOOC platform can be set up with different levels of difficulty, such as entry level, proficiency level and proficiency level, according to learners' level of knowledge mastery.In addition, the online course platforms should have guidance and recommendation functions, which use big data technology to accurately push the more suitable course resources to learners individually, and guide learners to solve the technical problems encountered in practice, so as to make the use of the platforms more humanized and personalized.

In the process of browsing and learning course resources, some auxiliary learning tools are indispensable. The development of such application tools can enhance learners' willingness to continous use through creating a good and pleasant user experience, e.g., note-taking tools, flaw sweeper, etc.

Provide trial service for learners and give more favorable discounts to college students. The price-setting of paid courses is an important factor that can not be ignored. Compared with the adults who have job and income, the college students mostly get living expenses from their parents with little extra money as remaining. Therefore, they may be deterred by the relatively high cost even they think some courses are useful. Price would be an obstacle to online learning for college students. The results of this study also show that college students think that the courses on some online course platforms are too expensive, which has a significant negative impact on the willingness to continuous use. Therefore, it is suggested that online service providers should provide free trial service for learners for a better understanding of the value of the paid courses and the corresponding services they can enjoy. At the same time, it is also recommended that giving appropriate discounts for college students, so that they can have more access to the high-quality courses suitable for them.
This study has a few limitations. For example, based on the purpose of this study, the number of samples in the study may not be sufficient. In the future, the study will investigate the students who have taken online courses in different universities, so as to increase the sample size of the study and make the research results more representative. In addition, future studies will take into account the influence of learners' relevant attributes (such as major, learning interest, etc.) on the relationship between variables.This will help universities or online education institutions optimize online course platform, so as to give learners a good online learning experience.

\section{Compliance with Ethical Standards}

Conflict of interest Author Mengting Chen declares that she has no conflict of interest. Author Xuan Wang declares that she has no conflict of interest. Jixin Wang declares that he has no conflict of interest. Author Can Zuo declares that she has no conflict of interest. Author Jun Tian declares that she has no conflict of interest. Yongpeng Cui declares that he has no conflict of interest.

Ethical approval All procedures performed in studies involving human participants were in accordance with the ethical standards of the institutional and/or national research committee and with the 1964 Helsinki declaration and its later amendments or comparable ethical standards.

\section{References}

1. Akkoyunlu B, Soylu MY. A study of student's perceptions in a blended learning environment based on different learning styles. Educ Technol Soc. 2008;11(1):183-93.

2. Lei $\mathrm{Z}$, Jun $\mathrm{W}$. data analysis of national top online open courses on MOOC platform. Digit Educ. 2019;5(05):36-41.

3. Khechine H, Lakhal S, Pascot D, Bytha A. UTAUT model for blended learning: the role of gender and age in the intention to use webinars. Interdiscip J E-Learn Learn Objects. 2014;10(1):33-52.

4. Sarabadani J, Jafarzadeh H, ShamiZanjani M. Towardss understanding the determinants of employees' E-learning adoption in workplace: a unified theory of acceptance and use of technology (UTAUT) view. Int J Enterp Inf Syst (IJEIS). 2017;13(1):38-49.

5. Thongsri N, Shen L, Bao Y, Alharbi IM. Integrating UTAUT and UGT to explain behavioural intention to use M-learning: a developing country's perspective. J Syst Inf Technol. 2018;20(3):278-97.

6. Cheng B, Wang M, Stephen JHY, Peng J. Acceptance of competency-based workplace e-learning systems: effects of individual and peer learning support. Comput Educ. 2011;57(1):1317-33.

7. Schaik P. Unified theory of acceptance and use for websitesused by students in higher education. J Educ Comput Res. 2009;40(2):229-57.

8. Jan PT, Lu HP, Chou TC. The adoption of e-learning: an institutional theory perspective. Turk Online Journal Educ Technol TOJET. 2012;11(3):326-43.

9. Williams MD, Rana NP, Dwivedi YK, Lal B (2012) Is utaut really used or just cited for the sake of it? a systematic review of citations of utaut's originating article 
10. Liaw S-S. Investigating students' perceived satisfaction, behavioral intention, and effectiveness of e-learning: a case study of the Blackboard system. Comput Educ. 2008;51(2):864-73.

11. Al-Azawei A, Lundqvist K. Learner differences in perceived satisfaction of an online learning: an extension to the technology acceptance model in an arabic sample. Electron J e-Learn. 2015;13(5):408-26.

12. Brocke JV, Richter D, Riemer K (2009) Motives for using Social Network Sites (SNSs) \& An analysis of SNS adoption among students. bled econference.

13. Cho V, Cheng TCE, Lai WMJ. The role of perceived user-interface design in continued usage intention of self-paced e-learning tools. Comput Educ. 2009;53(2):216-27.

14. Altaher R, Atteih R. Quality of e-learning contemporary vision. Alexandria: Dar Algamaa Al Gadida; 2012.

15. Bhuasiri W, Xaymoungkhoun O, Zo H, Rho JJ, Ciganek AP. Critical success factors for e-learning in developing countries: a comparative analysis between ICT experts and faculty. Comput Educ. 2012;58(2):843-55.

16. Lin WS, Wang CH. Antecedences to continued intentions of adopting e-learning system in blended learning instruction: a contingency framework based on models of information system success and task-technology fit. Comput Educ. 2012;58(1):88-99.

17. de Sena Abrahão R, Moriguchi SN, Andrade DF. Intention of adoption of mobile payment: An analysis in the light of the Unified Theory of Acceptance and Use of Technology (UTAUT). RAI Revista de Administração e Inovação. 2016;13(3):221-30.

18. Kangnie (2017) Moocs were initially completely free. What about now?[EB/OL]. http://www.cedumedia.com/i/7737.html. Accessed 22 June 2017.

19. Kim H, Chan HC, Gupta S. Value-based Adoption of Mobile Internet: an empirical investigation. Decis Support Syst. 2007;43:111-26.

20. Chong AY. Understanding mobile commerce continuance intentions: an empirical analysis of Chinese consumers. Jt Int Conf Inf Sci. 2013;53:22-30.

21. Nunally JC. Psychometric theory. 2nd ed. New York: McGrawHill; 1978. p. 21.

22. Venkatesh V, Morris MG, Davis GB, Davis FD. User acceptance ofinformation technology: toward a unified view. MIS Q. 2003;27(3):425-78

23. Almahamid S, Aburub F (2011) Factors that determine continuance intention to use e-learning system: an empirical investigation. In: International conference on telecommunication technology and applications, Singapore, LACSIT Press, pp 242-246
24. Kim B. An empirical investigation of mobile dataservice continuance: incorporating the theory of plannedbehavior into the expectation-confirmation model. Expert Syst Appl. 2010;37(10):7033-9.

25. Hair JF, Ringle CM, Sarstedt M. PLS-SEM: indeed a silver bullet. J Mark Theory Pract. 2011;19(2):139-52.

26. Hair JF, Black WC, Babin BJ, Anderson RD, Tatham RL. Multivariate data analysis. New Hersey: Prentice-Hall; 2006.

27. Bentler PM, Bonett DG. Significance tests and goodnessof fit in the analysis of covariance structures. Psychol Bull. 1980;88(3):588-606.

28. Fornell C, Larcker DF. Evaluating structural equation models with unobservable variables and measurement error. J Mark Res. 1981;18(1):39-50.

29. Taylor AB, Mackinnon DP, Tein JY. Tests of the three-path mediated effect. Organ Res Methods. 2008;11(2):241-69.

30. Preacher KJ, Hayes AF. Asymptotic and resampling strategies for assessing and comparing indirect effects in multiple mediator models. Behav Res Methods. 2008;40:879-91.

31. Heinrichs JH, Lim KS, Lim JS, Spangenberg MA. Determining factors of academic library web site usage. J Am Soc Inform Sci Technol. 2007;58(14):2325-34.

32. Lee YC. An empirical investigation into factors influencing the adoption of an e-learning system. Bioinformatics. 2013;31(5):1701-7.

33. Green DT, Pearson JM. Integrating website usability with the electronic commerce acceptance model. Behav Inf Technol. 2011;30(2):181-99.

34. Loo WH, Paul YHP, Chong SC. User acceptance ofMalaysian government multipurpose smartcard applications. Gov Inf Q. 2009;26(2):358-67.

35. Wong KT, Teo T, Russo S. Interactive whiteboard acceptance: applicability of the utaut model to student teachers. Asia-pacific Educ Res. 2013;22(1):1-10.

36. Cheng YM. Effects of quality antecedents on e-learning acceptance Internet. Internet Res. 2012;22(3):361-90.

37. Sharma SK, Chandel JK. Technology acceptance model for the use of learning through websites among students in oman. Int Arab J Inf Technol. 2013;3(1):44-9.

Publisher's Note Springer Nature remains neutral with regard to jurisdictional claims in published maps and institutional affiliations. 